\title{
Analogue to Digital Telecare: Findings and Themes from a User-Centred Study to Help People Live in the Community Safely
}

\author{
Andrea Taylor \\ Glasgow School of Art \\ Moray, UK \\ a.taylor@gsa.ac.uk
}

\author{
Hugh Pizey \\ Glasgow School of Art \\ Glasgow, UK \\ h.pizey@gsa.ac.uk
}

\author{
Craig Whittet \\ Glasgow School of Art \\ Glasgow, UK \\ c.whittet@gsa.ac.uk
}

\author{
David Hammond \\ Chiptech \\ Lancaster, UK \\ david@chiptech.uk
}

\author{
Stephen Milne \\ CENSIS \\ Glasgow, UK \\ stephen.milne@censis.org.uk
}

\begin{abstract}
Telecare services include personal alarms, home sensors and activity monitoring to enable people to remain safe and independent in their own home. Telecare has traditionally used analogue connectivity, however internationally, there is a shift to digital connectivity. This presents a rare opportunity to fundamentally redesign telecare, address current barriers to uptake, and help more people live in the community safely. This paper describes a user-centred study to design innovative digital telecare concepts, involving key stakeholders (a supplier, a manufacturer, 13 end users, 32 informal carers and 29 health and social care professionals). There are currently limited examples of digital telecare internationally. The main contributions of this paper are: an overview of key challenges and opportunities for telecare, not emphasised in existing literature within the context of the analogue to digital switchover; findings from user engagement activities, which identified issues that may be more important to users when designing telecare (e.g. self-concept) and less important (e.g. privacy); and the synthesis of ideas generated through the design process, which identified four themes that should prove useful to practitioners and researchers working in the field: community-based support, telecare you don't wear or notice, expand the use of telecare, and introduce telecare earlier.
\end{abstract}

Telecare. Technology enabled care. Assisted living technology. Telehealthcare. Older people.

\section{INTRODUCTION}

The delivery of health and social care is changing in response to a combination of factors including: an ageing population and the associated increase in the numbers of people living longer with longterm conditions; increasing pressure on health and social health care budgets to 'do more with less'; and changes in models of health care from reactive to preventive, hospital-centred to communitybased, clinician-centric to patient-centric and more recently, to consumer-centric. These changes are fuelling interest in the potential for technology, such as telecare, to support older people to remain safe and independent in their own home for longer and reduce utilisation of health services.

A range of understandings of telecare exist. This paper uses the TEC Services Association (TSA) definition: 'Telecare services include personal alarms, a wide range of home sensors (e.g. fire and flood detectors) and activity monitoring. Alerts are monitored by remote control centres that can respond quickly to emergencies' (www.tsavoice.org.uk/support-at-home). The TSA is the industry body for telecare services in the UK.
Although telecare is the term used in this paper, other terminology is used in the field such as Technology Enabled Care (TEC), assisted living technology (ALT) and telehealthcare.

Basic telecare typically comprises an alarm unit (hub); a pendant trigger worn with a neck cord, wrist strap or belt clip; and 24/7 alarm call handling. The hub incorporates an emergency alarm button and is plugged into the mains electricity supply and a home telephone line. Pressing the button on the hub alerts an Alarm Receiving Centre (ARC) that help is needed. Centre staff are able to talk with the caller through a speakerphone on the hub to decide on a course of action. For example, going straight to emergency services or involving those named on the caller's file such as a nearby informal carer (family member, friend or neighbour). Pressing the button on the pendant trigger also raises a call through the hub, provided it is within range (about 50 meters).

Enhanced telecare is more proactive than basic telecare and allows for automatic responses based on sensor information. For example, the following sensors can automatically raise an alarm call via the hub: a fall detector-an alarm is raised if the 
individual falls; a smoke detector; a bed sensoran alarm is raised if an individual gets out of bed and does not return within a preset time; an epilepsy sensor-an alarm is raised when a seizure is detected; a property exit sensor-an alarm is raised when an individual's door is opened during preset times e.g. night-time. A global positioning system (GPS) is used outside the home, typically for people with dementia. An alarm is raised via satellite technology when an individual has breached a designated safe area and their whereabouts can be tracked.

Governments in most developed countries have telecare programs in place (Turner and McGeeLennon 2013), reflecting the issue of an aging population around the world. The UK has an estimated 1.7 million end users and over 240 ARCs (TSA 2017). The main user groups for telecare are: people with telecare equipment in their home (end users); informal carers who are involved in/affected by telecare arrangements; and health and social care (H\&SC) professionals e.g. home care workers and community nurses who support end users. Usually, end users of telecare are older adults. However, telecare has to be designed to support adults of all ages with varying needs and capabilities e.g. young adults with learning disabilities.

\subsection{Telecare: Challenges and Opportunities}

\subsubsection{Analogue to Digital}

In the UK, telecare is built on tried and trusted technology: telephone line connectivity delivering voice and data. However, analogue telephone services will be switched off by 2025 as the UK's telecommunications infrastructure is upgraded to digital connectivity. Analogue systems using voiceband signalling will all be affected to some degree, including telecare. Once the analogue lines have been deactivated, the current telecare infrastructure becomes less robust. The challenge is to ensure that the transition from analogue to digital is well handled, and that the lives of vulnerable people are not put at risk. However, the shift presents a rare opportunity for a fundamental redesign of telecare, rather than a 'like for like' replacement. There are few examples of digital telecare deployments in the world (FarrPoint Ltd. 2016). There are deployments based on digital technology, but these are limited in scale and number, and tend to be standalone solutions separate from the main telecare systems. A successful digital solution is therefore desirable.

\subsubsection{Barriers to Uptake by End Users}

A substantial body of research has shown that while many end users view telecare positively, many do not accept and/or use it as intended, and many potential users are reluctant to take it up (Hamblin 2016; Yusif, Soar, and Hafeez-Baig 2016; Stewart and McKinstry 2012; Clark and McGee-Lennon 2011; Taylor and Agamanolis 2010). Commonly cited barriers to the adoption and optimal use of telecare include: stigmatising and conspicuous equipment; unattractive equipment; the equipment is too easily activated accidentally; the cost of services; reluctance to use the equipment to disturb ('bother') call operators or informal carers; forgetting to wear equipment; a lack of knowledge or awareness about telecare; a perceived lack of need; and concerns around personal and data privacy.

Several of these problems were reported over 15 years ago (Blythe, Monk, and Doughty 2005). A contributing factor to a lack of innovation in the design of telecare is the limited interoperability between manufacturers' products: equipment supplied by one manufacturer can only 'talk' to equipment supplied by that same manufacturer. Interoperability is important because many people have a package of care (more than two items). Consequently, service providers such as local authorities are to an extent locked-in to a particular manufacturer (no competition, no innovation), and users may not have access to the equipment most suitable to their needs. Further, despite numerous studies emphasising the importance of engaging more closely with users, manufacturers have typically not done so, viewing their customer as the service providers who bulk buy and provide the equipment (Taylor et al. 2012). However, the move to digital telecare requires new technical standards, opening up new opportunities. For example, Procter, Wherton, and Greenhalgh (2018) recommend the development of more bespoke telecare solutions, as people have highly individual needs.

\subsubsection{False Calls}

H\&SC participants in our study reported that the number of false alarm calls is as high as $80 \%$ for the pendant trigger, $87 \%$ for the fall detector, and $73 \%$ for the property exit sensor. This is important due to the cost to services to respond to calls in instances of uncertainty. A high number of false calls is also reported in much earlier research, indicating little has been achieved to address this challenge. For example, in a study with a telecare mobile warden service, the highest category of calls logged was reported as "false alarm" (Blythe, Monk, and Doughty 2005), and in a study with two ARCs in England, a teleoperator described the incoming calls from fall detectors as "all false calls" (Roberts, Mort, and Milligan 2012). Both studies reported that end users would often deliberately raise an alarm in order to have social contact. A commonly cited reason for false calls relates to technical design. For example, a study of falls in older people concluded that the sensitivity of fall detectors needs to be reduced, as they are too easily activated (Horton 2008). There is therefore a design opportunity to reduce false calls.

\subsubsection{Cost Savings}

Health and social care budgets are under significant pressure in most countries. Thus, telecare requires 
not only to be economical for end users, but also offer cost savings in health and social care budgets. In the UK, telecare can be accessed privately through product retailers or directly from suppliers or manufacturers, without recourse to local authorities, but the consumer market for it remains underdeveloped (Yeandle 2014). However, that some are willing to act as consumers of such products may indicate the existence of untapped demand for products and services that the telecare market could exploit more effectively than at present (Yeandle 2014). There is therefore an opportunity to stimulate consumer demand, particularly among older people aged $50+$ years who hold an estimated $77 \%$ of the UK's financial worth (Centre for Ageing Better 2019).

\subsection{The Innovation Challenge}

This paper describes a user-centred research study conducted in the city of Glasgow, Scotland, UK. The study was funded via a mechanism that enables public sector bodies to connect with organisations from different sectors to provide innovative solutions to specific public sector challenges. In this case, the public sector body was Glasgow City Health and Social Care Partnership (GCHSCP). Health and Social Care Partnerships are partnerships between the local authority and National Health Service (NHS). The challenge was to research and design new digital telecare solutions. The study team comprised a telecare manufacture, a Higher Education Institution (HEI), and an innovation centre that specialises in Sensor and Imaging Systems and Internet of Things (IOT) technologies. This paper contributes to the body of work within $\mathrm{HCl}$ on assisted living technology. The main contributions are:

- Findings from user engagement activities, which identified those issues that may be more important and less important to users when designing telecare, to help ensure telecare is accepted and used.

- The synthesis of ideas generated through the design process, which identified four themes that should prove useful to other practitioners and researchers seeking to improve the acceptance and use of telecare: community-based support; telecare you don't wear or notice; expand the use of telecare; and introduce telecare earlier.

- An overview of the key challenges and opportunities for a fundamental redesign of telecare, which are not emphasised in existing literature within the context of the planned analogue to digital switchover.

\section{RELATED WORK}

The previous section of this paper includes related work on barriers to the uptake of telecare by end users. This section briefly describes other related research work.

\subsection{AKTIVE Project}

The AKTIVE (Advancing Knowledge of Telecare for Independence and Vitality in Later Life) project explored how telecare can be developed to help older adults live a full and independent life, and benefit those caring for them, both paid and unpaid carers (AKTIVE). The AKTIVE project focused on two specific groups of older adults: those susceptible to falls and those with memory problems or dementia. The central study was called Everyday Life Analysis (ELA). ELA involved repeat research visits over six to nine months with a sample of 60 participants aged 65+ years living in two localities in England, UK. The study explored how participants experienced telecare and used or under-used equipment, including barriers to adoption.

Hamblin (2016) used the data collected from the ELA study to examine how it corresponded to an American model of 'obtrusiveness' where obtrusiveness is something which is undesirably prominent. The obtrusiveness model was created by Hensel, Demiris, and Courtney (2006) in relation to ALTs and comprises eight dimensions, each of which have subcategories (Table 1). Hamblin found that the model is largely applicable to the UK context, and identified two further issues that affect the acceptance and use of telecare: the degree of control an end user feels they have, and the information and support they receive in using their equipment. Hamblin concluded that the obtrusiveness model plus the additions (control and information) highlight important issues that can assist H\&SC professionals in ensuring telecare is accepted and used.

Our study also analysed research data collected via user engagement activities using the obtrusiveness model, plus the two additions identified by Hamblin. The findings are presented in the Results and Discussion section. Our study builds on the work of Hensel, Demiris, and Courtney (2006) and Hamblin (2016) by applying the model to the Scottish context for the first time to our knowledge, and finds that the model and additions are applicable. Our study found an additional factor affecting the acceptance and use of telecare: a fear or dislike of new technology. Although a much smaller study, our study also builds on the work of Hamblin by working with a general adult population rather than specific sub-groups within the population.

Table 1: The obtrusiveness model

\begin{tabular}{|l|l|}
\hline Dimension & \multicolumn{1}{|c|}{ Subcategories } \\
\hline Physical & Functional dependence \\
\cline { 2 - 2 } & Discomfort \\
\cline { 2 - 2 } & Excessive noise \\
\hline
\end{tabular}




\begin{tabular}{|l|l|}
\hline \multirow{4}{*}{ Usability } & Obstruction \\
\cline { 2 - 2 } & Aesthetic incongruence \\
\hline \multirow{5}{*}{ Privacy } & Lack of user friendliness or accessibility \\
\cline { 2 - 2 } & Additional demands on time and effort \\
\cline { 2 - 2 } & $\begin{array}{l}\text { Invasion of personal information } \\
\text { home }\end{array}$ \\
\hline \multirow{5}{*}{$\begin{array}{l}\text { interaction } \\
\text { Human }\end{array}$} & Inaccuration personal space of the \\
\cline { 2 - 2 } & $\begin{array}{l}\text { Restricted distance/time away from } \\
\text { home }\end{array}$ \\
\cline { 2 - 2 } & Perceived lack of usefulness \\
\cline { 2 - 2 } & $\begin{array}{l}\text { Threat to replace in-person visits } \\
\text { emergencies }\end{array}$ \\
\cline { 2 - 2 } & Negative effects on relationships \\
\hline Self-concept & Symbol of loss of independence \\
\cline { 2 - 2 } & Cause of embarrassment \\
\hline Routine & Interference with daily activities \\
\cline { 2 - 2 } & Acquisition of new rituals \\
\hline Sustainability & Affordability concerns \\
\cline { 2 - 2 } & Concern about future needs \\
\hline
\end{tabular}

\subsection{Athene Project}

The ATHENE (Assistive Technologies for Healthy Living in Elders: Needs Assessment by Ethnography) project aimed to produce a richer understanding of the needs and lived experiences of older people, and how they and their informal carers can work with ALT stakeholders-suppliers, health and social care professionals-to coproduce ALTs (ATHENE). The research team proposed that making successful ALTs relies on collaboration, involving not only formal carers but also informal ones, whose role has gone unnoticed by technology designers. In particular, the project focused on the role of 'bricolage' (pragmatic customization, combining new with legacy devices) by informal carers, in enabling ALTs to be personalised to individual needs. The research team concluded that a new research agenda is needed, focused on solving challenges of involving users and their informal carers in the co-production of ALTs. Our study also employs a user-centred approach, involving user research and collaboration among telecare stakeholders including informal carers, to inform the design of products and services. However, our study's focus is on the challenges and opportunities arising from the transition from analogue to digital telecare.

\subsection{The Development of AAL Systems}

Hallewell Haslwanter, and Fitzpatrick (2017) investigated the reasons for the limited number of Ambient Assisted Living (AAL) technologies on the market. AAL systems include sensor-based systems e.g. to monitor if a person has fallen and raise an alarm, and ambient systems e.g. to detect activity in the home. The authors focused on engaging with experts involved in the development of AAL systems, rather than end users, to understand the problems development teams encounter. A total of 71 issues were identified by participants. The most important issues included: not really understanding the needs of the user group; lack of overview of the players/which projects have been developed; and communication problems between project partners/stakeholders. Regards the first issue, the authors found the solution to be more complex than developers "just being more user centred" e.g. a lack of access to older users was identified. Our study employed a user-centred design approach to better understand the needs of users, but similarly encountered a challenge with access to end users. Specifically, a concern by GCHSCP, who facilitated access to participants, about involving vulnerable older adults in research.

\section{METHOD}

The study employed a user-centred design approach. Specifically, it followed a Double Diamond design process involving four stages: Discover, Define, Develop and Deliver (Design Council 2005). The study was conducted by 29 4th Year MEng Product Design Engineering students (hereafter called designers) from the $\mathrm{HEI}$, supported and supervised by the study team. In addition, a researcher at the HEI with experience in telecare helped to oversee the project and synthesise the study results into research contributions. The designers were grouped into seven teams and worked on the project for 1.5 days per week for 11 weeks, involving field research and studio-based learning and teaching. The main methods of design used in the study are listed in Table 2. Ethics approval for the study was obtained from the Research Ethics Committee at the HEl and informed consent was obtained for all participants.

Table 2: Qualitative methods of design used in the study

\begin{tabular}{|l|l|}
\hline \multicolumn{1}{|c|}{ Method } & \multicolumn{1}{c|}{ Description } \\
\hline $\begin{array}{l}\text { Focus } \\
\text { groups }\end{array}$ & $\begin{array}{l}\text { Opinions, feelings and attitudes are } \\
\text { gauged from a group of participants } \\
\text { about a product, service etc }\end{array}$ \\
\hline Observation & $\begin{array}{l}\text { Attentive looking and systematic } \\
\text { recording of phenomena, including } \\
\text { people, artefacts and environments }\end{array}$ \\
\hline $\begin{array}{l}\text { Mind } \\
\text { mapping }\end{array}$ & $\begin{array}{l}\text { Visually organizing a problem or a topic } \\
\text { space in order to better understand it } \\
\text { Affinity }\end{array}$ \\
$\begin{array}{l}\text { Research observations and insights } \\
\text { are captured on post-it notes and } \\
\text { clustered based on infinity, which form } \\
\text { into themes }\end{array}$ \\
\hline Personas & $\begin{array}{l}\text { Personas consolidate archetypal } \\
\text { descriptions of user behaviour }\end{array}$ \\
\hline
\end{tabular}




\begin{tabular}{|c|c|}
\hline & $\begin{array}{l}\text { patterns captured into representative } \\
\text { profiles }\end{array}$ \\
\hline Storyboards & $\begin{array}{l}\text { Visual narratives that generate } \\
\text { empathy and communicate the } \\
\text { context in which a product, service } \\
\text { etc. will be used }\end{array}$ \\
\hline Scenarios & $\begin{array}{l}\text { A narrative that explores the future } \\
\text { use of a product or service etc. from a } \\
\text { user's point of view }\end{array}$ \\
\hline $\begin{array}{l}\text { Simulation } \\
\text { exercises }\end{array}$ & $\begin{array}{l}\text { Deep approximations of conditions, } \\
\text { designed to forge an immersive, } \\
\text { empathic sense of real-life user } \\
\text { experiences }\end{array}$ \\
\hline Prototyping & $\begin{array}{l}\text { The tangible creation of artefacts at } \\
\text { various levels of resolution, for } \\
\text { development and testing of ideas }\end{array}$ \\
\hline
\end{tabular}

\subsection{Participants}

Seventy-four adults representing the main user groups for telecare described in the Introduction section participated in the study: 13 end users (11 female, 2 male); 32 informal carers (29 female, 3 male); and $29 \mathrm{H} \& \mathrm{SC}$ professionals (16 female, 13 male). In addition, the designers engaged with five individuals with severe learning and physical disabilities ( 2 female, 3 male). These individuals did not use telecare, rather they represented extreme potential users; in considering their needs, the designers were encouraged and inspired to design solutions that are more usable by everyone. Participants were recruited via GCHSCP.

\subsection{Design Process}

\subsubsection{Discover Phase}

The Discover phase is about opening upgathering inspiration and developing initial ideas. This phase began with a demonstration of telecare equipment by H\&SC professionals with experience of prescribing and installing equipment, to support the designers to build knowledge of telecare and identify its strengths and weaknesses. Next, the designers engaged with telecare users. For logistical reasons, the designers formed into five research teams, with each team visiting one research venue. All the findings were subsequently shared among the seven design teams.

The first research team engaged with end users at a retirement housing community for older people, where homes are fitted with telecare equipment linked to the ARC in Glasgow. The next three research teams engaged with informal carers at three carer centres (one centre each), covering different areas of Glasgow. The centres provide a range of services including information, advice and respite care. The format of the sessions was focus groups within a communal space, lasting two hours. The fifth research team visited a day care service for adults with severe learning disabilities. The format of the session was semi-structured observation and discussion within a communal space. The research team observed members of staff interact with clients, clients interact with technology such as eye tracking software, and discussed clients' needs and capabilities with respect to telecare with staff.

The Discover phase also included a visit to the ARC in Glasgow to enable the designers to experience the service first hand, and to a technology demonstrator flat. The ARC visit included a demonstration of receiving an alarm call. The technology demonstrator flat is based in a multistorey building that supports older people who are facing isolation and loneliness, or circumstances that mean they are having trouble living full and active lives. The flat was set up to showcase the different ways older people can be supported to live independently in their own homes for longer, including through use of technology.

At each of these venues, research data was collected using field notes and photographs. Data was also captured using a storyboard method at the retirement housing community and carer centres. The designers sketched visual narratives of a day in the life of individual participants, based on their accounts, to better understand their experiences. To bolster the (first-hand) research data, a set of five personas was provided by GCHSCP. The personas were built on qualitative information and portrayed users of telecare with different needs. Each persona comprised a name, a (stock) photo, a short biography and description of their behaviours and the technology they use. Staff from GCHSCP's telecare team participated in a brainstorming session, involving the generation and discussion of multiple ideas in response to each persona. The data gathered during the Discover phase was analysed using design analysis methods such as mind mapping and affinity diagramming, and structured into problem statements and initial design ideas.

\subsubsection{Define Phase}

The Define phase is about focusing downsynthesising a mass of ideas into a reduced number of concept designs. During this phase, the design teams defined a direction (challenge area) to focus on from all the possibilities identified in the Discover phase and identified key ideas to develop further. The process was supported by generative design methods, e.g. scenarios, which helped the teams to carefully consider how their ideas could improve people's lives, as well as build consensus and understanding among the team members. The process included desk research and site visits to the collaborating innovation centre to investigate existing technological solutions for the areas the design teams wished to address. The Define phase ended with an interim presentation attended by members of the study team. Each design team presented their research findings and concept designs for constructive feedback and a steer on which design to develop further. 


\subsubsection{Develop Phase}

The Develop phase is about opening up-iteratively developing and testing the concept designs. The design teams revisited the retirement housing community and two of the three carer centres to gather feedback on their chosen concept designs. It was not possible to revisit the third carer centre due to scheduling difficulties. The sessions followed the format of the previous engagements (Discover Phase). The designers also engaged with telecare $\mathrm{H} \& S C$ professionals. The format of the session was a design critique within the design studios at the $\mathrm{HEI}$. Participants were divided into small groups, then on a rotating basis, each design team met with each group of participants to present their concept designs for constructive feedback (Figure 1). Participants comprised staff from the H\&SCP, the carer centres, the learning disabilities service who were accompanied by three of their clients, the $A R C$, and the technology demonstrator flat.

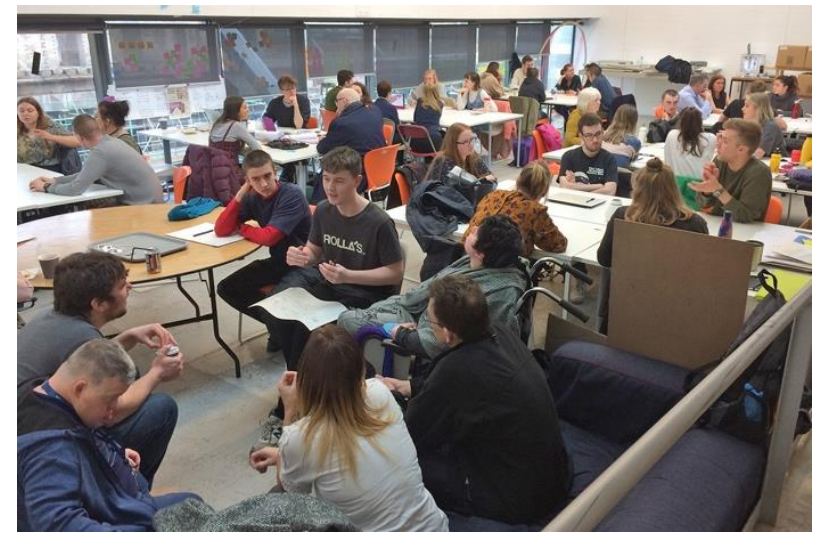

Figure 1: User engagement activity

At each of these engagement sessions, responses to the concept designs were collected using field notes. The feedback was used to inform the iterative development of the design teams' concept designs using design methods such as prototyping and simulation exercises. For example, one of the design teams used an 'ageing body suit' located at the technology demonstrator flat to help develop their concept design. The suit restricts mobility, simulating the deteriorated agility e.g. stooped back and arthritis that is associated with aging. The Develop phase ended with a second interim presentation and critique attended by members of the study team.

\subsubsection{Deliver Phase}

The Deliver phase is about focusing downfinalising the resultant product, service or system. The design teams focused on final prototyping, branding (positioning and naming, logotype and colour usage), producing technical specifications and costings, and preparing presentation materials such as 3D models and information boards for a showcase event to share their research findings and final concept designs. The Deliver phase ended with the showcase, which was attended by stakeholders who had participated in the study. Following the showcase, each design team compiled a detailed report on the design process. Each report comprised approximately 100 pages (A4 size) of user research data, visualisations (e.g. mind maps, storyboards, scenarios) and design ideas.

\subsection{Synthesis of Findings and Design Ideas}

As noted, a researcher with experience in telecare helped oversee the study. At the conclusion of the design process, the researcher synthesised the data collected/generated into research contributions. Specifically, the data that was synthesised comprised the findings from the user engagement activities and the ideas generated through the design process.

\subsubsection{User Engagement Findings}

User research data was primarily collected by the designers during the Discover and Develop phases. The data was analysed by the researcher using deductive content analysis, based on the conceptual framework (obtrusiveness model) by Hensel, Demiris, and Courtney (2006), plus the two additions (control and information) identified by Hamblin (2016). To begin, an Excel spreadsheet was created with a column for each of the codes (dimensions and subcategories) of the obtrusiveness model plus the additional codes 'control' and 'information'. The researcher then manually extracted all the user research data from the design teams' reports into the relevant codes (columns) in the Excel spreadsheet. Open coding was also used to allow for the inclusion of additional factors. This enabled the researcher to clearly identify the most important issues relating to acceptance/uptake of telecare, as reported by participants.

\subsubsection{Design Ideas}

Each design team delivered one final concept design i.e. there were seven concept designs in total. However, throughout the design process a multitude of ideas were generated and explored based on research. These ideas, expressed in words/phrases and images, were analysed by the researcher using affinity diagramming. To begin, the researcher re-read each of the design teams' reports several times. Each idea was then manually extracted (written) onto individual post-it notes, which were placed on a large sheet of paper. The post-it notes were then clustered based on affinity, which gave rise to the overarching themes. Finally, the theme categories were named and summarised, and checked with other members of the study team.

\section{RESULTS AND DISCUSSION}

\subsection{User Engagement Findings}

This section presents the synthesised findings from the user engagement activities. Unless reported, 
participants did not describe any issues relating to particular dimensions or subcategories.

\subsubsection{Physical Dimension}

A few participants reported issues related to excessive noise. For example, one participant commented "I don't like the noise of the alarm". Several participants reported issues related to the aesthetic incongruence of telecare, in particular its unattractive and jarring appearance and "medical aesthetic". One participant commented that the pull cord is "ugly, outdated and a monstrosity".

\subsubsection{Usability Dimension}

Lack of user friendliness or accessibility was a major issue for participants. The majority of problems related to activation of devices due to physical or cognitive conditions, or learning difficulties. For example, one participant with arthritis commented "My fingers don't work well sometimes and I can't press the button", and one participant with early stage dementia commented "I forget why it's there and press it out of curiosity, then throw it into the bin when it I don't see it do anything. When the responders arrive, I get angry and confused". Participants also reported that devices were easily activated by accident. For example, one participant commented "The pendant goes off all the time and it takes the alarm forever to shut off". The main accessibility issue related to the standard practice of installing a single hub in an end user's home. Participants reported they cannot always hear the hub and/or be understood by the ARC if they are in another room. A couple of participants reported that additional demands on time and effort were needed to charge GPS devices daily.

\subsubsection{Function Dimension}

Many participants reported problems with false calls from inaccurate measurement of devices, particularly from fall detectors, property exit sensors and smoke alarms. For example, one participant commented "the smoke alarm goes off so often that I have cakes and biscuits ready for the firemen!". In terms of restricted distance or time away from home, many participants reported that the pendant trigger only works within range of the hub limiting its usefulness in large houses/gardens or away from home. A few participants reported a perceived lack of usefulness. For example, one participant from the retirement housing community who had deactivated their telecare system, commented "I don't feel that I need it".

\subsubsection{Human Interaction Dimension}

A single participant reflected that asking for help from friends and family had negative effects on relationships by making her feel that she was "no longer an equal". Of note, staff at the ARC in Glasgow described a number of issues related to a lack of human response in emergencies. Originally there were four call centres in Glasgow, all serving local communities where staff and residents were familiar to each other. The centres then merged into a single centre, serving the whole of Glasgow where staff no longer have the same local knowledge of residents or geography of the area. Consequently, staff are less able to make decisions based on being knowledgeable about the client, which other research has also found to be important (Proctor et al. 2016), and travelling (response) time is longer.

\subsubsection{Self-concept Dimension}

Self-concept was another major issue for participants. Many participants viewed the uptake and usage of telecare as a symbol of loss of independence. For example, one participant reported that her family had organised the installation of telecare, i.e. it wasn't her choice, and that made her feel "less independent, I'm not dead yet!". Participants also described telecare as a cause of embarrassment. For example, participants commented that the pendant trigger "screams I am vulnerable" or "shouts I need assistance", and that it makes them feel like "an inconvenience" to ARC responders and emergency services in particular, especially in instances of false calls, as "they have more important things to do".

\subsubsection{Sustainability Dimension}

Many participants raised affordability concerns. Historically, local authorities have provided telecare services free of charge, however many have now introduced charges. In 2013, GCHSCP introduced a weekly charge (£3) for its telecare service, which sparked a strong negative reaction: approximately $3,000(30 \%)$ of its service users cancelled the service. Some participants commented that they couldn't afford the service e.g. "it's a luxury I can't afford". Others commented that they are paying for a "safety net": something that they pay for all of the time, which they might only need it some of the time in an emergency. For some, this was not worth the cost-benefit.

\subsubsection{Control and Information and Support Dimensions}

The control dimension was cited by a single participant as a concern, whose family had arranged for telecare to be installed in their home. This had made them feel "inferior, it's a constant reminder of my condition". The information and support dimension was also an issue for some participants. For example, some participants were unclear on how to use the equipment and where it works and doesn't work. Many of the carers were unaware of the products that could help them support the person they cared for to live independently, indicating the need to improve awareness of existing products and services through health and social care channels, and as touched upon earlier, consumer channels. 
Overall, the findings of the user engagement activities indicate that the model of obtrusiveness by Hensel, Demiris, and Courtney (2006) plus the additions identified by Hamblin (2016) are applicable to the Scottish context. An additional issue was identified: a fear or dislike of new technology. For example, one participant commented "I have an iPad, but I haven't opened it and I don't have any desire to", and another participant with a basic (nonsmart) phone commented "I don't like touchscreens". Although a much smaller study, our findings are broadly similar to the study by Hamblin (2016). Neither study identified significant issues with functional dependence on telecare or obstruction, invasion of personal information, threat to replace inperson visits or interference with daily activities, suggesting these dimensions may be less important to users when designing digital telecare. Conversely, both studies identified issues with the other dimensions, in particular the self-concept dimension.

\subsection{Themes}

Four themes were identified from the synthesis of ideas generated through the design process:

- Community-based support

- Telecare you don't wear or notice

- Expand the use of telecare

- Introduce telecare earlier.

This section presents each theme, illustrated with one of the design teams' final concept designs, as an example of an approach that could be taken. All of the designs have an emphasis on attractive and less stigmatising products and services, and utilise low-cost technology to help ensure affordability. For example, several of the designs use LoraWAN, a wireless networking standard to support the IoT that offers long-range connectivity and low power operation cost (LoRA Alliance).

\subsubsection{Community-based Support}

The first theme is that of utilising community-based support to make telecare less reliant on traditional organisational requirements such as ARCs. Arguably, successful telecare relies on the existence of social networks and the availability of hands on care. Indeed, other researchers have noted a key paradox of telecare is that while it is intended to work at a distance and to be of particular value to people who do not have robust networks of co-present caring others, it will only function well when they are situated within such networks (Proctor et al. 2016). The AKTIVE project proposed that support networks for telecare users that draw on neighbours, friends or people known through local associations (e.g. a church group) give some strength to relatively "weak ties", which are theorised as especially productive of social cohesion (Yeandle 2014). Further, for policymakers and practitioners, ensuring older people have the opportunity to sustain and develop networks of weak ties may be important for future planning of support systems capable of assisting large numbers of frail older people to live safely and independently in their communities (Yeandle 2014). A comparable conclusion of the UK Government's Whole System Demonstrator (WSD) programmethe largest randomised control trial of telecare and telehealth in the world-is that organisational requirements around telecare, such as arrangements for monitoring and responding to alarm calls, requires review if it is to become costeffective (Newman, 2011).

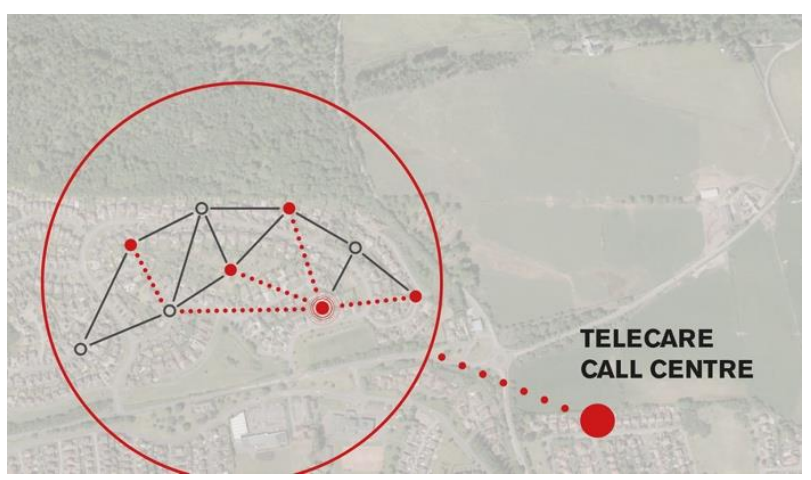

Figure 2: A local CommuniCare network of support

The value and potential of community-based support is illustrated in the CommuniCare concept design. CommuniCare envisions the creation of 'connected communities' where people are embedded within local networks of support for telecare. Each agreeing household has a Beacon (hub) and a set of Seeds (pendant triggers) that can be placed around the home (Figure 2). The Seeds communicate with the Beacon and each Beacon communicates with the other Beacons in the network and with the ARC via LoRaWAN and GSM SIM technologies. The more Beacons the stronger the network of support. In an emergency, the telecare user raises an alarm via the Beacon or Seed. While the community network fulfils the primary responder role, the ARC will monitor all calls and respond as necessary. The Beacon may also be used for non-emergency communications with other Beacons in the network. For example, seeking companionship or help with practical tasks. Such communications are not monitored by the ARC and could help older people combat loneliness and isolation.

\subsubsection{Telecare You Don't Wear or Notice}

The second theme identified was that of making telecare equipment less noticeable (obtrusive) to encourage acceptance and usage. Several of the design teams concluded that an intrinsic problem with the most common form of telecare equipment, the pendant trigger, is that end users need to be willing to wear it. However, as noted, the findings of 
this and other research has indicated that many end users choose not to wear their pendant and/or other wearable device (e.g. a fall detector) or they forget to put it on. In response, several of the design teams explored two directions: ambient and voice sensing technologies-removing the need for end users to be wearing a device and/or to be capable of pressing a button when help is needed; and interoperability with mainstream home technology products connected to the Internet such as smart speakers e.g. Amazon Alexa and Google Home-to help remove the noticeability of telecare equipment, and encourage people to consider purchasing consumer technologies rather than a telecare equipment package from their local authority.

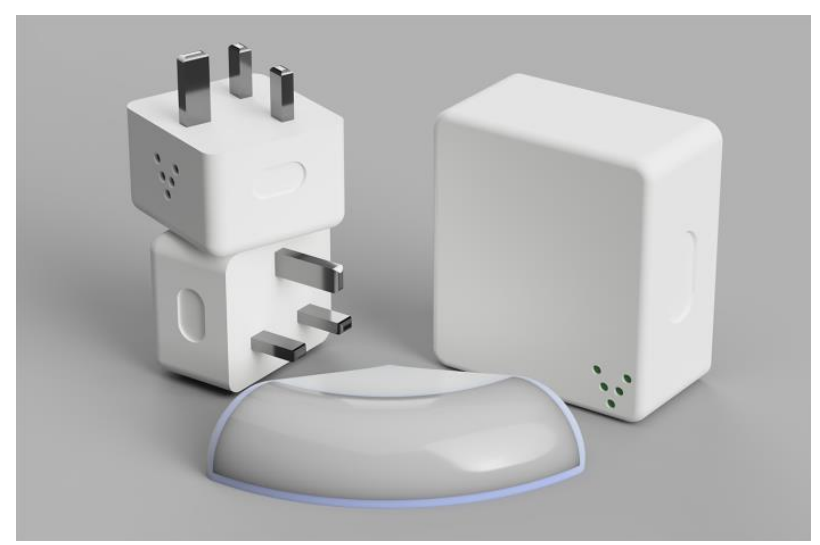

Figure 3: The Evolve vHUB (right), vSENSE (bottom), VSPEAK (top left) and vSMARTPLUG (bottom left)

The value and potential of a non-wearable solution is illustrated in the Evolve concept design (Figure 3). Evolve envisions the creation of an unobtrusive home-based system, comprising the vHUB (hub), vSENSE, vSPEAK and vSMARTPLUG equipment. The vSENSE is a PIR sensor array that detects and monitors human movement including falls detection and property exits, as well as extreme temperature changes, and automatically raises an alarm call to the ARC e.g. in the event of a fall. vSENSE uses low resolution imaging to allay potential privacy concerns about 'spying'. The vSPEAK is an electric plug with a built-in speaker/microphone and voice recognition that allows users to voice-enable an alarm call to the ARC and communicate with Centre Staff. Finally, the vSMARTPLUG is an electric plug with a built-in speaker that connects to vSENSE, and alerts the user to plug in their GPS device for charging and/or take it with them when they exit the property.

\subsubsection{Expand the Use of Telecare}

Currently, telecare is aimed at people experiencing more severe declines and/or much older people, and is therefore addressing a relatively small population. The third theme was the potential to expand the use of telecare beyond those who are normally thought of as typical users. Several of the design teams explored new products and services that are desirable and functional for everyone, irrespective of age or ability. In particular, the use of telecare for overnight support (sleepovers) was explored. Sleepovers are designed to meet a range of needs including support where a person: has a significant mental health problem or learning disability that means it is difficult for them to be alone overnight; needs a call/conversation to reassure or check-in; or might wander or leave the house. In the UK, the cost to employ a social care worker for sleepover hours has increased markedly due to a change in legislation around how staff are paid, representing a ripe opportunity area to potentially introduce telecare.

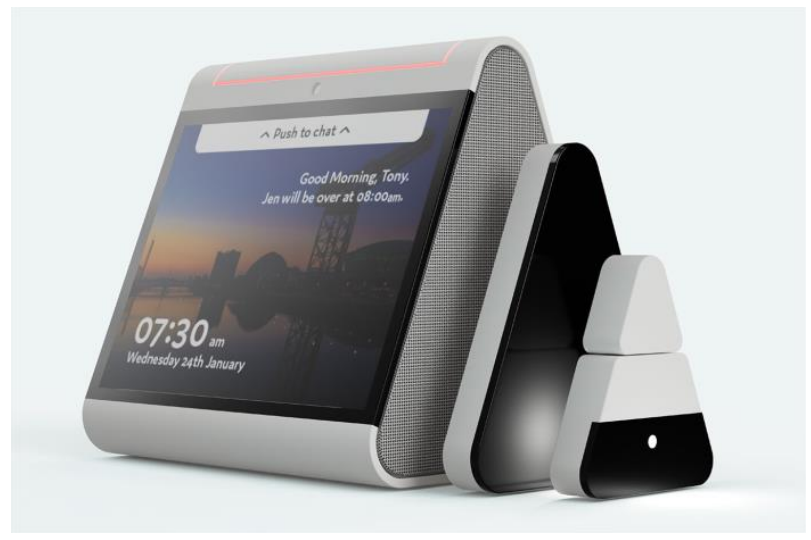

Figure 4: The Snooze Safe bedside hub (left), and property exit sensors (right)

The value and potential of telecare for sleepovers is illustrated in the Snooze Safe concept design (Figure 4). The system comprises a bedside hub, a property exit device, monitoring software and a mobile application (app). Snooze Safe removes the need for sleepover staff to stay overnight at the user's home. The hub uses XeTHru sensor technology to detect breathing rate and movement in order to track whether the user is in bed, and issues that are more common in people with learning disabilities such as epilepsy and sleeping problems. The hub also incorporates video calling with sleepover staff as a means to provide reassurance or check-in. For example, if the user is feeling anxious, they can make a video call and staff can offer reassurance/a human response. In the event of an emergency, the hub or property exit device automatically raises an alarm call to the ARC through the app on the user's phone using cellular and short-range wireless (Z-Wave) technologies. Monitoring data is sent to a user interface on the Snooze Safe app for sleepover staff to respond to, with the aim of keeping the user healthy in their homes for longer.

\subsubsection{Introduce Telecare Earlier}

The final theme relates to the earlier introduction of telecare as a pro-active choice rather than in reaction to a crisis (a 'push' situation). As described in the previous sections of this paper, there are a range of factors that affect the acceptance and use 
of telecare, including a fear or dislike of new technology. Some older adults are reluctant to adopt new technologies in later life that they are not familiar with, particularly when implemented in response to a time of crisis. In response, several of the design teams explored two directions: technology that end users want to acquire earlier in the life course, with a focus on prevention-so that in the event of a crisis, users are already engaged and familiar with the technology should additional equipment be required; and the concept of modularity, where the technology is flexible enough to suit the changing needs and abilities of end users as they age.

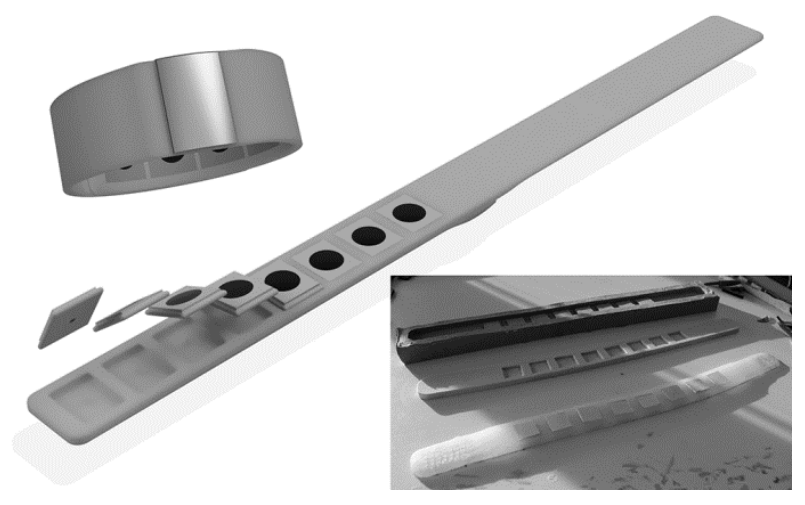

Figure 5: The Exila band and early prototypes (right)

The value and potential of more modular solutions is illustrated in the Exila concept design. Exila is a wearable personal trigger with eight slots for individual sensors to be inserted, a built-in speaker/microphone, and a mobile app (Figure 5). Exila combines cellular (CAT-M1 standard) and Bluetooth technologies to enable voice communication with the $\mathrm{ARC} / \mathrm{responder}$, via the wearable itself or the user's mobile phone respectively-allowing Exila to be used away from the home. Accordingly, two slots are dedicated to a SIM card and Bluetooth sensor. Examples of options for the other slots, as prototyped by the designers, include a GPS sensor for locating the end user in an emergency, heart rate sensor, temperature sensor, and accelerometer. The Exila app consolidates and visualises the data generated by the sensors, to support end users to take preventive action to maintain independence and continue living at home.

While other countries are planning digital telecare deployments, there are currently very limited examples of digital telecare internationally. Thus, there is very limited best practice and availability of digital solutions on the market (FarrPoint 2016). However, the decommissioning of analogue telephone services internationally means it is likely that a significant number of countries will need to start deploying digital telecare. This presents an important opportunity for the field of $\mathrm{HCl}$ to help address this immense problem and improve the acceptance/use of telecare. The four broad themes identified through our study should prove useful to other practitioners and researchers seeking to improve the acceptance and use of telecare.

\subsection{Limitations}

A limitation of the study is the gender imbalance in participants, where only five out of 45 (11\%) participants across two of the user groups-end user, informal carers-were male. This is largely due to the very small number of men who participated in events at the retirement housing community and attended the carer centres. Therefore, the results of the study may be less representative of the target population than is desirable. However, a roughly equal number of male and female H\&SC professionals participated in the study. Ideally, the study would have included more end users to increase its validity. However, as suggested by Hallewell Haslwanter and Fitzpatrick (2017), a set of personas built on user research was provided to the designers to supplement their own user research.

\section{CONCLUSION}

Telecare plays an important role in enabling people to remain safe and independent in their own home for longer, and most developed countries have telecare programs in place. Telecare has traditionally used analogue connectivity, however internationally, there is a shift to digital connectivity. This presents a rare opportunity to fundamentally redesign telecare, address current barriers to uptake, and help more people live in the community safely. This paper describes a user-centred study on digital telecare involving multiple stakeholders. The main contributions to the field of $\mathrm{HCl}$ are: an overview of the key challenges and opportunities for a fundamental redesign of telecare; findings from user engagement activities, which identified issues that may be more important and less important to users when designing telecare; and identification of four themes that should prove useful to other practitioners and researchers seeking to improve the acceptance/use of telecare: community-based support; telecare you don't wear or notice; expand the use of telecare; and introduce telecare earlier.

\section{ACKNOWLEDGEMENTS}

We thank all those who were involved, with particular acknowledgement to the designers of the concepts presented in this paper: Alistair Byars, Robert Mueller, Steph Parker and Samuel Watson (CommuniCare); Rebecca Jones, Isobel Leason, Africa Perez and Christopher Welch (Evolve); Jay van den Hoven, Rachael Hughson-Gill, Joe Pollard and Chiara Rossi (Exila); Jemma Brown, Scott Neill, Michael O'Donnell and Jessica Vinnels (Snooze Safe). SBRI (Small Business Research Initiative) funded the study. 


\section{REFERENCES}

AKTIVE. "Advancing knowledge of telecare for independence and vitality in later life project". Accessed 29 April 2021. https://aktive.org.uk

ATHENE. "Assistive technologies for healthy living in elders: Needs assessment by ethnography". Accessed 29 April 2021. http://atheneproject.org.uk

Blythe, M., Monk, A., and Doughty, K. 2005. "Socially dependable design: The challenge of ageing populations for $\mathrm{HCl}$." Interacting with Computers 17(6), 672-689. doi:10.1016/j.intcom.2005.09.005

Centre for Ageing Better. 2019. "Industrial challenge fund healthy ageing challenge framework". Accessed 29 April 2021. https://www.ageingbetter.org.uk/sites/default/files/2019-02/HealthyAgeing-Challenge-Framework.pdf

Clark, J., and McGee-Lennon, M. 2011. "A stakeholder-centred exploration of the current barriers to the uptake of home care technology in the UK." Journal of Assistive Technologies 5(1), 12-25. doi: 10.5042/jat.2011.0097

Design Council. 2005. "A study of the design process". Accessed 29 April 2021. https://webarchive.nationalarchives.gov.uk/2008 0821071137/http://www.designcouncil.org.uk/Do cuments/About\%20design/Eleven\%20Lessons/P DF\%20Eleven\%20Lessons_complete_study.pdf

FarrPoint Ltd. 2016. "International landscape review on the shift from analogue to digital in telecare". Accessed 29 April 2021. https://telecare.digitaloffice.scot/media/58a2fc6e d39fd083f55d4182bf88826d.pdf

Hallewell Haslwanter, J.D., and Fitzpatrick, G. 2017. Issues in the Development of AAL Systems: What experts think. 10th International Conference on PErvasive Technologies Related to Assistive Environments (PETRA '17), 201208. https://doi.org/10.1145/3056540.3056554

Hamblin K. 2016. "Telecare, obtrusiveness, acceptance and use: An empirical exploration." British Journal of Occupational Therapy 80(2), 132-138. doi:10.1177/0308022616667751

Hensel, B.K., Demiris, G., and Courtney, K.L. 2006. "Defining obtrusiveness in home telehealth technologies: A conceptual framework." Journal of the American Medical Informatics Association 13(4), 428-31. doi:10.1197/jamia.M2026

Horton, K. 2008. "Falls in older people: The place of telemonitoring in rehabilitation." Journal of Rehabilitation Research and Development 45(8), 1183-94.

LoRa Alliance. Accessed 29 April 2021. https://loraalliance.org/about-lorawan
Martin, B., and Hannington, B. 2012. Universal methods of design. Rockport Publishers

Newman, S et al. 2011. "The whole System Demonstrator Programme." Accessed 29 April 2021.

https://www.city.ac.uk/_data/assets/pdf_file/000 3/243066/WSD_Exec_Sum_28th_20Aug.PDF

Procter, R., Wherton, J., and Greenhalgh, T. 2018. "Hidden work and the challenges of scalability and sustainability in ambulatory assisted living." ACM Transactions on Computer-Human Interaction 25(2):11, 1-26. doi:10.1145/3185591

Proctor, P., Wherton, J., Greenhalgh, T., Sugarhood, P., Rouncefield, M., and Hinder, S. 2016. "Telecare call centre work and ageing in place." Computer Supported Cooperative Work 25(1), 79-105. doi:10.1007/s10606-015-9242-5

Roberts, C., Mort, M., and Milligan, C. 2012. "Calling for care: 'Disembodied' work, teleoperators and older people living at home." Sociology 46(3), 490-506. doi:10.1177/0038038511422551

Stewart, L., and McKinstry, B. 2012. "Fear of falling and the use of telecare by older people." British Journal of Occupational Therapy 75(7), 304-312. doi:10.4276/030802212X13418284515758

Taylor, A., and Agamanolis, S. 2010. "Evaluation of the user experience of a standard telecare product - the personal trigger." 2010 Second International Conference on eHealth, Telemedicine, and Social Medicine 51-56. doi:10.1109/eTELEMED.2010.15

Taylor, A., Bernard, L., Pizey, H., and Whittet, C. 2012. "TeleWEAR: Engaging users and suppliers of telecare in product design." $\mathrm{CHI}$ "12 Extended Abstracts on Human Factors in Computing Systems 2637-2642. doi:10.1145/2212776.2223849

TSA. 2017. "A digital future for technology enabled care?" Accessed 29 April 2021. https://aace.org.uk/wpcontent/uploads/2017/11/TSA-301664Whitepaper_Oct17-120917_ONLINE-VERSIONONLY_0.pdf

Turner, K., and McGee-Lennon, M. 2013. "Advances in telecare over the past 10 years." Smart Homecare Technology and TeleHealth 1, 21-34. doi:10.2147/SHTT.S42674

Yeandle, Sue. 2014. "Frail older people and their networks of support: how does telecare fit in?" $\begin{array}{llll}\text { Accessed } & 29 & \text { April } & 2021 .\end{array}$ https://www.ageing.ox.ac.uk/download/61

Yusif, S., Soar, J., and Hafeez-Baig, A. 2016. "Older people, assistive technologies, and the barriers to adoption: A systematic review." International Journal of Medical Informatics 94, 112-6. doi:10.1016/j.ijmedinf.2016.07.004 